termetallics and thus gradually decrease the storage capacity. A pure $\mathrm{LaNi}_{5}$ storage unit, e.g., when cycled in $\mathrm{H}_{2}+0.5 \% \mathrm{O}_{2}$ at r.t., loses about $30 \%$ of its capacity within 100 absorption/desorption cycles due to the decomposition of $\mathrm{LaNi}_{5}$ into $\mathrm{La}_{2} \mathrm{O}_{3}$ and $\mathrm{Ni}$. The binding of the impurities to the intermetallic is of course a purification of $\mathrm{H}_{2}$. The addition of some $\mathrm{Al}$ improves the stability of $\mathrm{LaNi}_{5}$ towards surface decomposition considerably: $\mathrm{LaNi}_{4.7}$ $\mathrm{Al}_{0.3}$ is less reactive with oxygen and the losses of capacity at room temperature about 10 times smaller. The surface decomposition is of course harmless in closed systems, in which the same $\mathrm{H}_{2}$ is absorbed and desorbed cyclically. However, when $\mathrm{H}$-absorption/desorption was controlled thermally at constant pressure, the (reversible) disproportionation of $\mathrm{LaNi}_{5}$ into $\mathrm{La}$ hydride and Ni was observed above $200^{\circ} \mathrm{C}$.

$\mathrm{FeTi}$ has been run in a closed system over 30000 cycles without noticeable deterioration. In $\mathrm{Mg}_{2} \mathrm{Ni}$, sintering at the rather high temperature of desorption can cause problems.

\section{REFERENCE}

For references the reader is referred to the "Proceedings of the Int. Symp. on Properties and Applications of Metal Hydrides", J. Less Common Metals 73, 74 (1980) and 88, 89 (1982).

\title{
14th EGAS Conference
}

\section{Annual Meeting of the European Group for Atomic Spectroscopy}

The annual meeting of the European Group for Atomic Spectroscopy (EGAS), organized by Professor N. Grevesse and coworkers, took place in the last week of July 1982, at the University of Liège. We were more than 150 participants from 16 countries. The traditional style of EGAS meetings of having a small number of invited talks (five in this case) and many contributed papers and poster sessions which were included for the first time at Orsay in 1979 was followed. Poster sessions have become popular because they give more time for discussion and they avoid parallel sessions which always pose problems to those who wish to concentrate on the topics that concern them personally.

Laser spectroscopy continues to play a dominant role at EGAS meetings. $H$. Walther reported on recent advances in this area: heterodyne detection of Rydberg atoms' maser emission, single atom detection, hfs and transfer collisions between states, etc.
The problem of hertzian coherence in spectroscopy can be considered a normal topic for EGAS meetings, and now the interest in nonlinear aspects is increasing. W. Lange discussed different recent techniques: sideband spectroscopy, pulse train spectroscopy, quantum beats in transmission. Other results, such as the pressureinduced Hanle-effect, were also covered.

Particle accelerators with fast ion beams have become in the past decade a clearly identified field of atomic physics. In particular, the beam foil spectroscopy technique is one of the most versatile and powerful methods of measuring excitation and ionization energies. J. Désesquelles reviewed developments in this area with emphasis on highly ionized atoms and highly excited states: Rydberg and multiple excited levels; f-value measurements in isoelectronic systems with a small number of valence electrons and in elements of solar or stellar importance, and zero field quantum beat fine structure measurements.

\section{New Members of the European Physical Society}

\section{INDIVIDUAL MEMBERS}

\section{Category 4 a)}

J.-P. Delrue, Mons, B

W. Götze, Baldham, D

C. Passow, Karlsruhe, D

\section{Category 4c)}

Austrian Physical Society

G. Bauer, Leoben

H. Kirchmayr, Vienna

Belgian Physical Society

F.G. Binon, Grand-Lancy, $\mathrm{CH}$

J.-M. Gilles, Mont St. Guibert

\section{Eötvös Lorand Physical Society}

I. Bakonyi, Budapest

I. Mojzes, Budapest

\section{Finnish Physical Society}

T. Alvesalo, Espoo

A. Anttila, Helsinki

A.-M. Häkkinen, Helsinki

J. Lenkkeri, Oulu

J. Parkkinen, Kuopio

M. Roos, Helsinki

P. Soininen, Helsinki

German Physical Society

U. Buck, Göttingen

K.-D. Ehrhardt, Jülich

D. Heitmann, Hamburg

H. Micklitz, Bochum

F.D.M. Pobell, Jülich

R. Rossmanith, Drested

S.W. Schulz, Hanau

Icelandic Physical Society

J. Petursson, Reykjavik

\author{
French Physical Society \\ F. Abeles, Paris \\ J.-P. Cohen-Addad, Grenoble \\ B. Deler, Plaisir \\ B. Djafari Rouhani, Lille \\ A. Fontaine, Orsay \\ E. Guyon, Limours \\ C. Jouanin, Montpellier \\ D. Leclerc, Caen \\ C. More, Marseille \\ F. Ouvry, Paris \\ J.-C. Rivoal, Paris \\ J. Rossat-Mignod, Uriage \\ A. Thomy, Villers-Nancy \\ C. Vérie, Antibes
}

The Institute of Physics

N.H. Barker, Preston

B. Bleaney, Oxford

R.W. Cahn, Paris, F

A.G. Cannon, Chester

Sir R. Clayton, Stanmore

G.D. Conn, Edgware

C. Deehan, Glasgow

J.S. Hutton, Didcot

B.C. Long, London

T. Martin, Glasgow

M.C.M. O'Brien, Oxford

J.B. Olomo, lle-Ife, Nigeria

D. Sherrington, London

D.T. Swift-Hook, Ashtead

P.K. Sinha, Coventry

H.B. van der Raay, Birmingham

D. Waldren, London

Institute Ruder Boskovic

A. Dulcic, Zagreb
Israel Physical Society

M. Marinov, Moscow, USSR

B. Meirovich, Moscow, USSR

D.V.I. Roginsky, Jerusalem

I.K. Salahlekekonen, Beersheva

B. Weinerman, Leningrad, USSR

J. Zak, Haifa

Italian Physical Society

C. Di Castro, Roma

S. Vitale, Genova

The Netherlands' Physical Society

M. Hazewinkel, Amsterdam

P. Kramer, Eindhoven

T. Janssen, Groesbeek

Polish Physical Society

A. Lissowski, Warsaw

M. Skowronski, Warsaw

Portuguese Physical Society

S.K. Mendiratta, Aveiro

Spanish Royal Society of Physics

J.C. Antoranz, Madrid

A. Castellanos, Sevilla

J.L. Castillo, Madrid

E. Crespo, Madrid

F.J. De La Rubia, Madrid

V.A. Fairen, Madrid

J.J. Garcia-Sanz, Madrid

A. Linan, Madrid

E. Munoz, Madrid

M. Yuste, Madrid

I. Zuniga-Lopez, Madrid

Swedish Physical Society

S. Svensson, Göteborg
Swiss Physical Society

G. Burki, Sauverny

T.M. Rice, Zurich

\section{Category 4d)}

(American Physical Society)

A. Abbas, Rehovot, ISR

C.F. Barenghi, Eugene

F. Calaprice, Princeton

J.L.S. Carvalho, Rio de Janeiro, Brazil

M.J. Clouter, St. John's,

Newfoundland, Can.

J.E. Demuth, Yorktown Heights

R.M. Martin, Palo Alto

D.F. Measday, Vancouver, Can.

G. Mitchell, Raleigh

J.W. Norbury, Moscow

J. Petersen, Halden, $N$

V. Raftopoulos, Toledo

B. Richter, Stanford

E.K. Riedel, Seattle

\section{ASSOCIATE MEMBERS}

British Telecom Research Labs.

Martlesham Heath

Ipswich IP5 7RE, Suffolk, UK

CNRS - Centre National de la

Recherche Scientifique

129 rue de I'Université

F-75700 Paris

\section{Société MATRA}

Centre de Montigny

F-78182 St Quentin-en-Yvelines

ONERA - Office National d'Etudes

et de Recherches Aérospatiales

POB 72

F-92322 Châtillon Cedex 
Other applications were also covered: molecular dissociation, atomic collisions in solids, super heavy element physics, spectroscopy of biomolecules.

M.J. Seaton reported on some astrophysical spectra observed in the ultraviolet region. Results obtained with the International Ultraviolet Explorer satellite (IUE) during the past $4 \frac{1}{2}$ years were reviewed. For long the attention of spectroscopists has been attracted by astronomical objects of low density because they contain many "forbidden" lines difficult to produce in the laboratory. Conversely astrophysicists obtain abundances of the chemical elements from quantitative spectrum analysis, notably $\mathrm{C}, \mathrm{N}$ and $\mathrm{O}$ which are of interest because $\mathrm{N}$ is produced from $\mathrm{C}$ and $\mathrm{O}$ in the course of hydrogen burning through the $\mathrm{CNO}$ cycle, whereas $\mathrm{C}$ is produced through helium burning in the triple- $\alpha$ process. The forbidden and resonance lines are excited by electron impacts and many have been observed which were not expected, because of their large excitation potentials.

Relativistic effects in atomic structure calculations were the subject of the invited talk of A. Hibbert who discussed recent progress in two types of calculation. Such effects can be treated as a perturbation on non-relativistic calculations in light and some heavier atoms. A fully relativistic treatment based on the Dirac or Dirac-Fock equation is necessary in heavy atoms. In this case the inclusion of core polarization effects has been considered. He also discussed some of the difficulties of obtaining accurate results.

Special sessions were held in memory of Professor D. Jackson and Dr. Erna Meinders - a former secretary of EGAS. Addresses were given in their honour by respectively A.P. Thorne and P.F.A. Klinkenberg.

In addition to invited and contributed papers, the tradition of round-table discussions was continued.

\section{Eusebio Bernabeu}

\section{Amendments to the Constitution and By-laws Agreed by Council in Copenhagen}

\section{ARTICLE 16}

The Council shall be composed in the following way:

a) as before / b) as before / c) as before /

d) delegates or representatives elected in accordance with the by-laws, by Associate Members mentioned in Article 6, as follows:

less than $50 \quad$ Associate Members: 3 representatives
$50-100$ Associate Members: 4 representatives
$100-150$ Associate Members: 5 representatives

\section{RULE 4}

$100-150$ Associate Members: 5 representatives

Honorary Members shall have the same right as Ordinary Members to attend meetings and subscribe to the publications of the Society. They shall not have the right to vote and they shall not be eligible for service on the Council. Admission to Honorary Membership shall be decided by the Council. The total number of Honorary Members at any one time shall not exceed fifty.

RULE 5

Each Associate Member shall have the right, as for an Ordinary Member, to send one representative to meetings and take out one subscription to the publications of the Society. Associate Members shall be represented in Council according to Article 16d) of the Constitution. Admission to Associate Membership shall be decided by the Council.

\section{RULE 18}

a) former RULE 18 is now 18 a)

b) former RULE 19 becomes now 18b)

RULE 19

Representatives on the Council of Associate Members - Constitution Article 6 - shall be elected by ballot from a list, provided by the Secretariat, of all nominations of individual candidates received from the Associate Members before 1 January of the year of the election. The ballot returns, with candidates arranged in order of decreasing number of votes obtained, then provide the names of that category of Council members, in the number required by Article $16 \mathrm{~d}$ ) of the Constitution - and also the names for those who may be needed later on to fill casual vacancies for unexpired term - always counting down the list, in the direction of decreasing strength of ballot votes received.

RULE 34

Any decision to change the value of the unit fee, shall be supported by three out of four votes cast. In this case the entitlement of votes of the members of Council shall be on the basis of the total units assessed under Rule 35 of these By-laws. Proxy voting shall be permitted.

Any proposal by the Executive Committee to increase the unit fee shall be submitted in writing to all Ordinary Members and Fellows at least three months before the Council is to meet to decide the matter.

The Divisional Chairmen and the representatives of Associate Members have no voting right for a change in the value of the unit fee.

\section{Delegates of Individual Members}

Following the postal ballot of the Individual Members of EPS, the following three new delegates to Council have been elected:

J. Ernest, Marcoussis, F

V. Heine, Cambridge, UK

F. Janouch, Stockholm, S with as first alternate:

H. Lotsch, Heidelberg, D
Delegates completing their three year term were M. Balkanski, A. Messiah and E.A. Müller. Delegates continuing are:

K. Bethge, Frankfurt/Main

J. Devreese, Antwerp

$\mathrm{H}$. de Waard, Groningen

F. Fumi, Genoa

J. Niederle, Prague

T. Riste, Kjeller
Europhysics News is the official joumal of the European Physical Society which comprises 29 National Socie ties, Academies and Groups, over 3000 Individua Members and 62 Associate Members. Governing bo dies of EPS are the General Meeting, Council and an elected Executive Committee responsible for detailed policy. EPS promotes the collaboration of physicists throughout Europe, organising and harmonising conferences, and promotes international exchanges in physics including participation in research and teaching activities abroad and attendance at schools. EPS publishes in addition to EN, Europhysics Conference blishes in addition to EN, Europhysics Conference
Abstracts, E. Ed. News and, in collaboration with The Institute of Physics (UK), the European Journal of Physics. Individual Members receive EN free of charge (price to institutions: Sw.Fr. $82 .-/ a$ ), rebates on the price of many publications and on conference fees. An nual EPS membership fee for Individual Members who belong to one of the EPS member societies for 1983 is Sw.Fr. 40.-; for independent members: Sw.Fr. 120.-

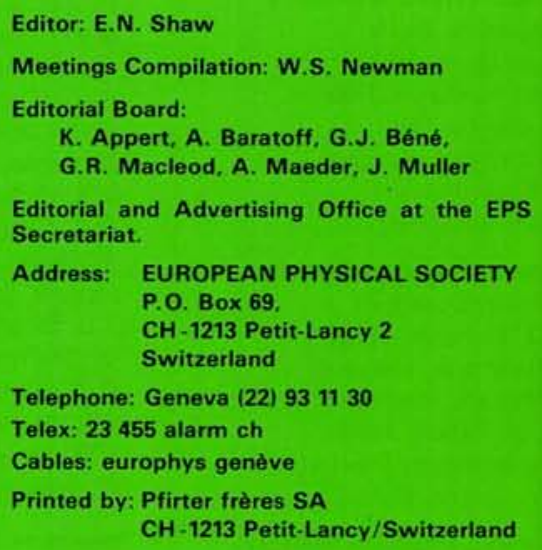

